\title{
Evaluation of seabed stability and scour control around subsea gravity protection structures
}

DOI:

10.1115/OMAE2010-20999

Link to publication record in Manchester Research Explorer

\section{Citation for published version (APA):}

Whitehouse, R. J. S., Lam, C., Richardson, S., \& Keel, P. (2010). Evaluation of seabed stability and scour control around subsea gravity protection structures. In Proceedings of the International Conference on Offshore

Mechanics and Arctic Engineering - OMAE/Proc Int Conf Offshore Mech Arct Eng - OMAE (Vol. 4, pp. 577-584). American Society of Mechanical Engineers. https://doi.org/10.1115/OMAE2010-20999

\section{Published in:}

Proceedings of the International Conference on Offshore Mechanics and Arctic Engineering - OMAE|Proc Int Conf Offshore Mech Arct Eng - OMAE

\section{Citing this paper}

Please note that where the full-text provided on Manchester Research Explorer is the Author Accepted Manuscript or Proof version this may differ from the final Published version. If citing, it is advised that you check and use the publisher's definitive version.

\section{General rights}

Copyright and moral rights for the publications made accessible in the Research Explorer are retained by the authors and/or other copyright owners and it is a condition of accessing publications that users recognise and abide by the legal requirements associated with these rights.

\section{Takedown policy}

If you believe that this document breaches copyright please refer to the University of Manchester's Takedown Procedures [http://man.ac.uk/04Y6Bo] or contact uml.scholarlycommunications@manchester.ac.uk providing relevant details, so we can investigate your claim.

\section{OPEN ACCESS}




\section{EVALUATION OF SEABED STABILITY AND SCOUR CONTROL AROUND SUBSEA GRAVITY PROTECTION STRUCTURES}

\author{
Richard J.S. Whitehouse \\ HR Wallingford \\ Howbery Park, Wallingford, \\ Oxfordshire OX10 8BA, United Kingdom
}

HR Wallingford

Level 28, AMP Building, 140 St Georges Terrace, Perth, WA 6000, Australia

\author{
Carlos Lam \\ University of Oxford \\ Department of Engineering Science, Parks Road, \\ Oxford OX1 3PJ, United Kingdom \\ Formerly: Fugro Ltd, Fugro House, Hithercroft \\ Road, Wallingford, Oxfordshire OX10 9RB, United \\ Kingdom
}

\section{Peter Keel}

Pipeshield International Ltd

4 Quay View Business Park, Barnards Way, Lowestoft, Suffolk NR32 2HD, United Kingdom

a case study from a subsea valve unit and concrete protection structure in the North Sea.

\section{SITE DESCRIPTION}

The site is situated in the southern North Sea (UK sector) in $29 \mathrm{~m}$ of water (to Lowest Astronomical Tide) with about $30.8 \mathrm{~m}$ of water at mean sea level and a spring tidal range of $2.3 \mathrm{~m}$. The predominant direction associated with the tidal current velocities was along the north-west / south-east axis and the depth-averaged spring tidal current speed was $0.53 \mathrm{~m} / \mathrm{s}$. Therefore the tidal ellipse is narrow with the semi-major axis $0.53 \mathrm{~m} / \mathrm{s}$ and the semi-minor axis $0.05 \mathrm{~m} / \mathrm{s}$. To represent site conditions the $1 / 12^{\text {th }}$ year total current speed was used in the present assessment following the standard empirical current profile [1], which has been found to fit well to a range of current observations and is used in offshore analysis:

$$
\begin{array}{ll}
U(z)=\left(\frac{z}{0.32 h}\right)^{1 / 7} \bar{U} & \text { for } 0<z<0.5 h \\
U(z)=1.07 \bar{U} & \text { for } 0.5 h<z<h
\end{array}
$$

where $z=$ height above seabed, $h=$ water depth and $\bar{U}=$ depth-averaged current speed. The profile of Equation 1 is used to determine the input current (Table 1) based on the depth-averaged velocity of approximately $0.7 \mathrm{~m} / \mathrm{s}$ at a height of $0.32 \mathrm{~h}$ above the bed. 
Table 1. Current profile variation with height $z$ above seabed.

\begin{tabular}{|c|c|c|}
\hline $\mathbf{z} / \mathbf{h}(-)$ & $\mathbf{z ~ ( m )}$ & $\begin{array}{c}\text { 1/12-year speed } \\
(\mathbf{m} / \mathbf{s})\end{array}$ \\
\hline 1.00 & 30.8 & 0.74 \\
\hline 0.75 & 23.1 & 0.74 \\
\hline 0.50 & 15.4 & 0.74 \\
\hline 0.30 & 9.2 & 0.68 \\
\hline 0.10 & 3.1 & 0.58 \\
\hline 0.05 & 1.5 & 0.53 \\
\hline 0.01 & 0.3 & 0.42 \\
\hline
\end{tabular}

The current profile from Table 1 is plotted in Figure 1 and for comparison the current profile for the 1 year return period current is shown which is about $16 \%$ faster in the upper portion of the water column.

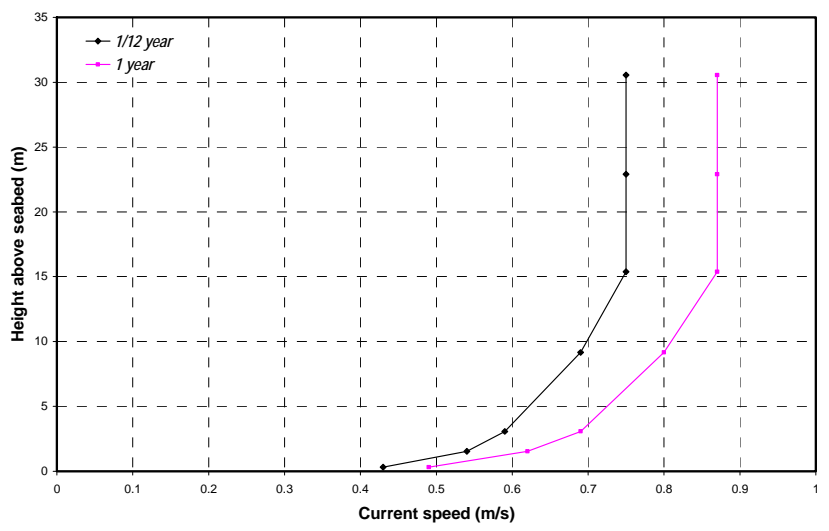

Figure 1. Current profiles.

From site investigation it was established that the seabed sediment parameters at site comprised very loose, very dark grey fine to medium sand with occasional shells and shell fragments. The conditions of the top two metres of the seabed are summarized in Table 2:

Table 2. Soil properties.

\begin{tabular}{|l|l|}
\hline Parameters & \multicolumn{1}{|c|}{ Values } \\
\hline & $\mathrm{d}_{10}=0.04 \mathrm{~mm}-0.09 \mathrm{~mm}$ \\
& $\mathrm{~d}_{30}=0.08 \mathrm{~mm}-0.18 \mathrm{~mm}$ \\
& $\mathrm{~d}_{50}=0.12 \mathrm{~mm}-0.20 \mathrm{~mm}$ \\
& $\mathrm{~d}_{60}=0.15 \mathrm{~mm}-0.21 \mathrm{~mm}$ \\
& $\mathrm{~d}_{90}=0.20 \mathrm{~mm}-0.29 \mathrm{~mm}$ \\
\hline \multirow{5}{*}{ Particle Sizading } & Coefficient of uniformity $\left(\mathrm{C}_{\mathrm{U}}\right)=$ \\
Characteristics & $\mathrm{d}_{60} / \mathrm{d}_{10}$ ranges from 2.33 to 3.75 \\
& - a $\mathrm{C}_{U}$ value less than 5 indicates a \\
& uniform soil, i.e. a high proportion \\
& of the particles have sizes within \\
\hline
\end{tabular}

\begin{tabular}{|l|l|}
\hline & narrow limits \\
\hline \multirow{5}{*}{ Density } & $\begin{array}{l}\text { Average Relative Density: } 20 \% \\
\text { Particle Density: } 2.68 \quad \mathrm{Mg} / \mathrm{m}^{3} \\
\text { (assumed) } \\
\text { Natural Wet Density: } 19.6 \mathrm{kN} / \mathrm{m}^{3} \\
\left(2.0 \mathrm{Mg} / \mathrm{m}^{3}\right) \\
\\
\text { Natural Dry Density: } 15.7 \mathrm{kN} / \mathrm{m}^{3} \\
\left(1.6 \mathrm{Mg} / \mathrm{m}^{3}\right)\end{array}$ \\
\hline \multirow{2}{*}{ Friction Angle } & $\phi^{\prime}=30^{\circ}$ (best estimate) \\
$\phi^{\prime}=25^{\circ}$ (lowest expected)
\end{tabular}

The information on soil parameters was combined with the information on hydrodynamics to determine the potential mobility of the bed material at site using existing methods [1] [2]. Assuming a water depth equivalent to mean sea level and a water temperature of $10^{\circ} \mathrm{C}$ and salinity of 35 , the depthaveraged current speed for mobilization of the median grain size of the seabed sediment is $0.51 \mathrm{~m} / \mathrm{s}$.

The method in [1] was used to determine the conditions for sediment to be mobilized and comparison was made to the currents at site. The surficial seabed sediment (very fine sand $\mathrm{d}_{50}=0.12 \mathrm{~mm}$ and fine sand up to $\mathrm{d}_{50}=0.20 \mathrm{~mm}$ ) will be mobilized by the mean spring tide which is greater than the calculated threshold value of depth-averaged current velocity of about $0.51 \mathrm{~m} / \mathrm{s}$ in $30.8 \mathrm{~m}$ of water. To put the assessment in context the associated values of bed shear stress required to mobilize sediment are $0.15 \mathrm{Nm}^{-2}$ and $0.18 \mathrm{Nm}^{-2}$ for the smaller and larger values of $d_{50}$ respectively. The depth-averaged spring tidal current speed and maximum currents from the south-east and north-west are capable of mobilizing sediment. For all the cases of extreme current the bed sediment is mobilized. Currents from other directions and all the neap-tide currents are not capable of mobilizing sediment.

The sensitivity to water temperature and angle of repose of the sediment was assessed. An increase in water temperature to $15^{\circ} \mathrm{C}$ reduced the threshold current speed less than $3 \%$ at site. Reducing the water temperature to $5{ }^{\circ} \mathrm{C}$ increased the threshold current by just over $3 \%$. The calculations assumed a value for angle of repose of the sediment (numerically equivalent to ø’) of around $30^{\circ}$. Most experimental tests of threshold have been done for $30^{\circ}$ or $32^{\circ}$. Our estimate is that in the looser sediment with a value of $25^{\circ}$ the threshold velocity will be approximately $10 \%$ smaller than the value given earlier. Therefore areas of less dense sediment may be mobilized at slightly lower current speeds.

Assessment of wind waves confirmed that frequently occurring (monthly on average) waves were capable of mobilizing (stirring-up) the surficial layer of seabed sediment even without the presence of currents. Therefore, sediment transport will occur more often than is indicated by the current and wave conditions alone. Also for situations where the current is below the threshold of motion but the wave height is above the threshold value, sediment stirred up by the waves 
will be transported in the direction of the current. The assessment of flow, waves and sediment parameters led to the conclusion that the seabed sediments are mobile under frequently occurring conditions and hence structures placed on the seabed will be susceptible to scour. This is because the flow interacts with the structures to generate a pattern of accelerated flow and turbulence which preferentially transports sediment from around the structure. The approach to scour assessment is described in [2]. The flow interaction for complex structures such as the cover units can be estimated through expert assessment but quantification requires the use of physical laboratory models of Computational Fluid Dynamics (CFD) models.

\section{SEABED STRUCTURES}

The site has a 16" pipeline which runs at an acute angle to the predominant tidal current flow direction and connects into a Wye-piece which is supported on a metal frame I-beam skid (Figure 2). The Wye-piece allows for a future pipeline tie-in. Once the Wye-piece had been installed on the seabed ROV video surveys showed a rippled sand bed and evidence of seabed sediment transport around the frame.

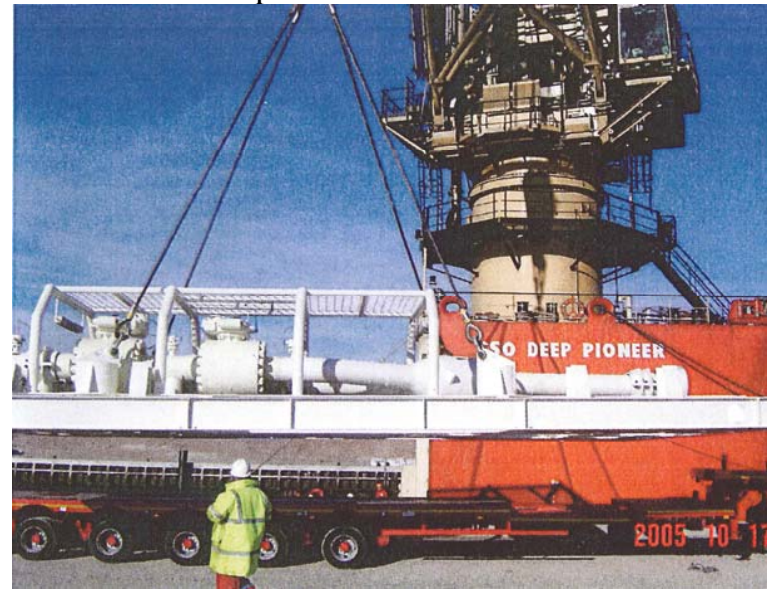

Figure 2. Wye-piece and skid.

The Wye-piece was covered with five pre-cast concrete gravity protection units to form one structure (Figure 3 ). The cover had overall dimensions of length $18.3 \mathrm{~m}$, width $13.8 \mathrm{~m}$ and height from seabed of $3.55 \mathrm{~m}$. The cover was fitted with 5 $\mathrm{m}$ by $3 \mathrm{~m}$ fronded mattresses to promote sedimentation adjacent to the sides of the structure. Figure 3 shows the frond mattresses rolled up along the sides of the footings ready for deployment by divers to be rolled and pinned on the seabed. To the right hand side of Figure 3 the opening for the pipeline to pass through one of the two end units is visible. Once installed on the seabed these openings faced south-east and north-west and hence were accessible to the regular action of the tidal flow described earlier in the paper. For operational reasons porch units abutting the openings were omitted during the original installation. The porch units were designed to reduce the flow that could enter into the cover.
Scour at the site commenced within a month of installation leading to some undermining of the Wye-piece skid and the footings of the cover, from flow in and around the openings and within the cover. Within four months observations showed scour induced settlement had taken place. Undermining of the Wye-piece skid and of the footings of the cover led to an overall settlement of the structure by about $1.25 \mathrm{~m}$ and the pipeline either side of the Wye-piece had become fully buried. The covers were removed as a temporary measure to enable a formal assessment of the original configuration and implementation of a revised design to reduce the future likelihood of scouring.

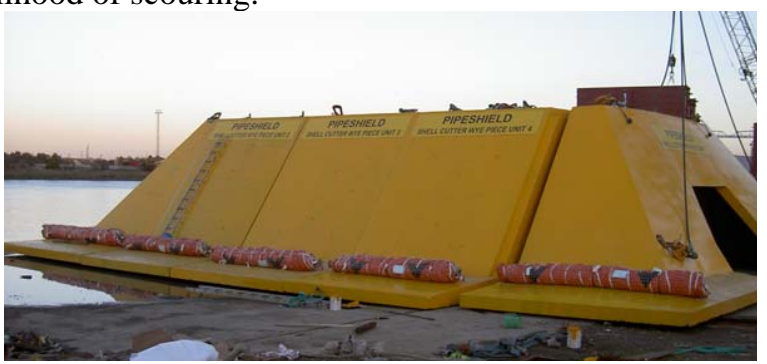

Figure 3. Concrete protection covers.

The revised works comprised gravel dumping to infill the scour hole around the Wye-piece, a carpet of pre-lay mattresses to form a consistent base for the concrete structure, i.e. the five cover units shown in Figure 3 and the sloping porches shown in Figure 4. The higher end of the porch is abutted to the end units of the main cover to provide an enclosure around the Wye-piece skid. Flexible concrete fronded mattresses were included in the design to be installed around all sides of the protection covers and adjacent to the sides and low openings of the porches. Laying these mattresses overlapping the footings of the structures and any pre-lay mattresses extending out and on the seabed thereby creates a smooth transition. An additional mattress layer was specified for installation at the porch openings to provide a reduced entry point for tidal flow. Fronded mattresses were also specified over the pipeline for a distance of $15 \mathrm{~m}$ away from the porch openings.

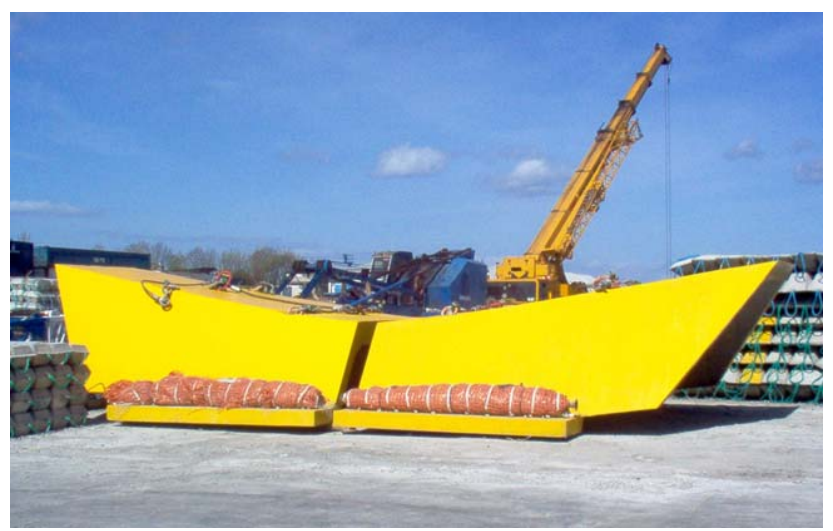

Figure 4. Porch units for concrete protection cover stored in yard; higher ends abut opening in Figure 3 when installed on the seabed. 
To understand the situation in which scour occurred, and to evaluate the reliability of the revised design in preventing a reoccurrence of scour, CFD modeling was completed.

\section{COMPUTATIONAL MODEL}

The CFD assessment was completed using the ANSYS CFX software package. This software solves the ReynoldsAveraged Navier-Stokes (RANS) equations using a turbulence model in 3-dimensions. The software is capable of simulating the required flow phenomena with a fully implicit and coupled algebraic multigrid solver, based on a tetra-prism-pyramid unstructured grid, which allows for stability in the numerical solution, and flexibility and convergence in the geometry construction.

The mesh can be controlled to allow mesh size and density to be varied across the domain. The mesh was enhanced in the areas of interest, around the pipeline and protection cover, to provide the appropriate level of mesh refinement for investigation of the flow field which could lead to scour. In the vertical, the computational mesh is also controlled; again allowing the required refinement to model the flow interaction with the structures of interest. The computational meshes used for these simulations were in the region of 2,000,000 to 2,500,000 elements. Model runs were carried out on a modern high specification personal computer.

The mesh was used to represent the solid geometry of the Wye-piece including the skid, concrete weights in the four corners, the pipeline and valve unit and tubular protection cage (Figure 5). The model build was extended to include the shelllike concrete cover (Figure 3) installed over the Wye-piece (Figure 2). Following the generation of the computational mesh, the physics for the simulation were input. A single-phase computation was used and the RANS equations were solved with a turbulence closure model. The k- $\omega$ SST turbulence model was chosen, as this has previously been reported to provide adequately resolved turbulence approximations, near bed and in adverse pressure gradients, for flow interaction and scour assessment [3].

The computational domain showing the proposed concrete cover configuration is represented in Figure 6, incorporating the internal arrangement of the pipeline and skid within the cover shown in Figure 5 . The computational domain was designed with a water depth of $20 \mathrm{~m}$ (representing only the lower section of the water column) and a plan area of $50 \mathrm{~m}$ by $80 \mathrm{~m}$, with the long axis of the domain aligned to the tidal current semi-major axis. The flow profile in Figure 1 is invariant above $15 \mathrm{~m}$ from the seabed and hence $20 \mathrm{~m}$ is considered sufficient for the present investigation of flow interaction with the protection structure. The cross-section area of the model domain through which the simulated flow passes is $1000 \mathrm{~m}^{2}$ and the cross section area of the cover units facing into the flow is approximately $50 \mathrm{~m}$. Based on experience in laboratory investigations [2] the 20:1 ratio exceeds the criterion for which blockage to flow does not lead to artificial effects in the flow field. This criterion applies equally to computational models.

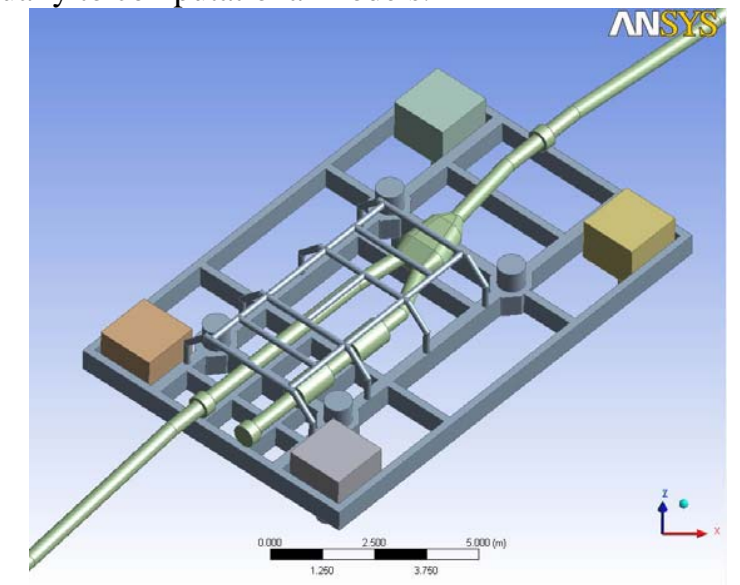

Figure 5. Internal representation of skid and pipeline within the concrete protection cover.

The boundary conditions on the seabed, pipeline, concrete protection structure and mattress were defined as solid wall (no slip) boundaries. The top of the computational domain had a free-slip boundary condition to simulate the less frictional effect of the free-surface. At the inflow boundary (e.g. southeast boundary), the current velocity profile was specified using the empirical formulae in (1). The sides of the computational domain (open to the sea) were set as zero relative pressure open boundaries, which allowed flow in and out of the domain, subject to the flow conditions within. The flow velocity profile for the simulations was specified at the inlet boundary and consequently adjusts as it passes through the domain and interacts with structures within the domain. From a cold start the model was run for sufficient time for the ambient flow to advect through the length of the domain which required a simulation time, based on the depth-averaged current, of around 160 seconds. Results for analysis were obtained later in the runs.

For each of the scenarios, the simulations were performed for 500 seconds, allowing any initial impulsive transients within the computational domain to propagate through and the generation of fully developed flow fields. Predictions of relevant quantities such as flow velocity, vorticity, bed shear stresses, turbulent kinetic energy and flow streamlines (defined using non-buoyant, zero density particle tracking) were analyzed to review the interaction of the flow with the structures and the consequent influence on sediment transport. The results were internally consistent and bed shear stress was used as this is the main driver for sediment transport [1]. The predicted areas of bed shear stress, or in the terminology used by ANSYS wall shear (i.e. in both cases the force exerted on the seabed by the flowing water), that have values greater than the threshold value will experience erosion.

Since the main focus was to analyze the bed shear stress around and within the concrete protection cover and consequently assess potential scouring of the seabed in the 
vicinity of the concrete protection cover it was necessary to validate the flow profile in the model with the tidal profile in Figure 1 . Three samples of the velocity profile were taken within the flow domain (Figure 6). The input boundary condition and the profile upstream of the structure are directly comparable (e.g. profiles "Input" and "Upstream of Cover" which overlay in Figure 8).

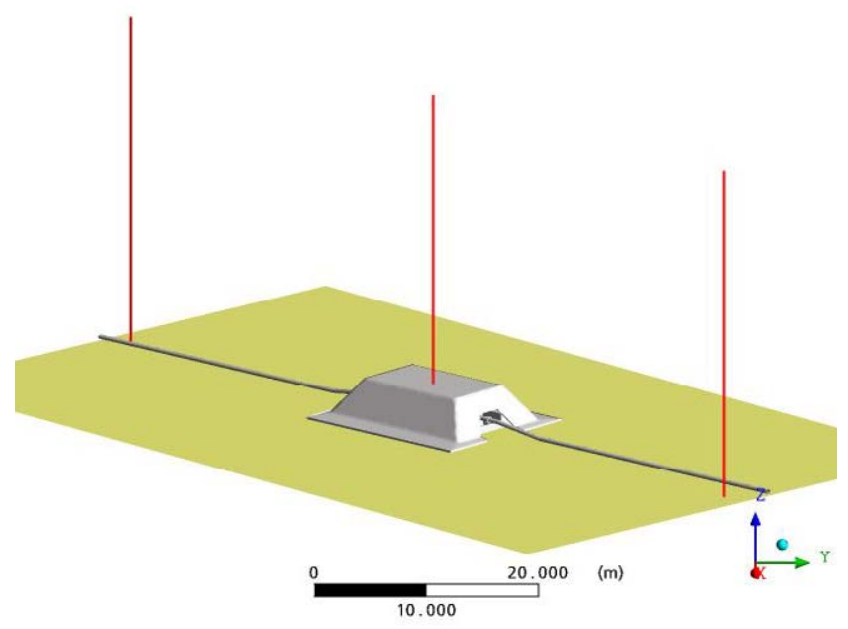

Figure 6. The concrete cover in place and location of velocity profile output locations - flow from bottom right to top left.

The model simulations were completed for two test scenarios, for the original and revised configurations. The model mesh for the revised configuration is shown in Figure 7.

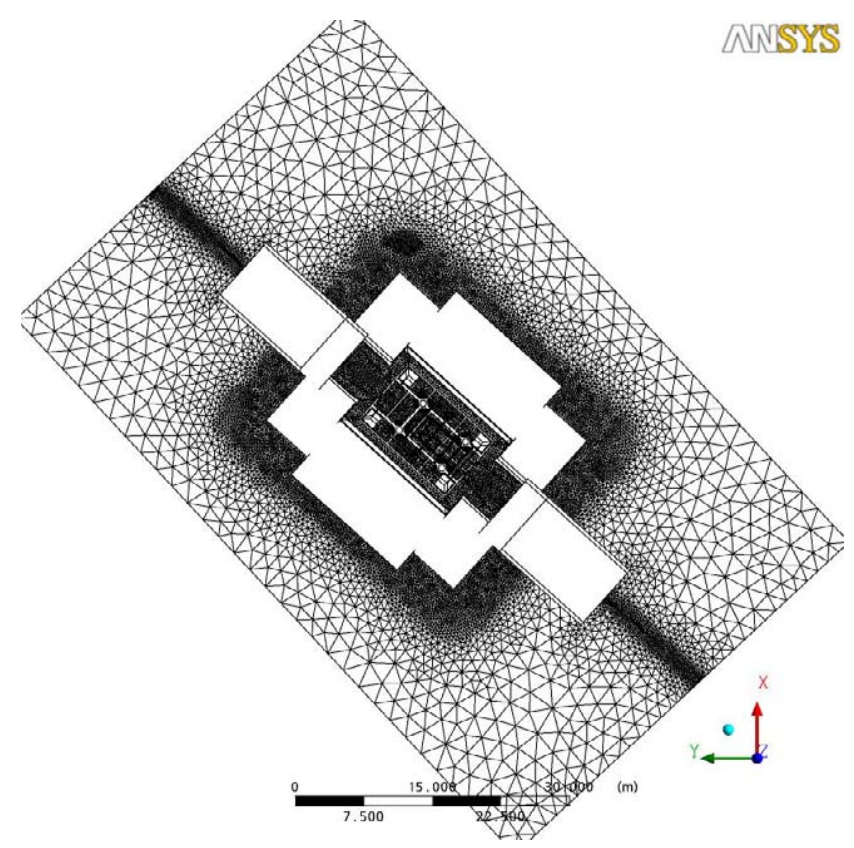

Figure 7. Model mesh plan view of revised structure.

\section{RESULTS FOR ORIGINAL STRUCTURE}

The model results confirmed the passage of flow through the concrete cover which shows velocities $1 \mathrm{~m}$ above the seabed. At this level flow was able to enter the cover and interact with the internal skid and pipework configuration. At 3 $\mathrm{m}$ above the bed the flow within the cover was relatively low, being above the level of the openings. The velocity profile centered on the concrete cover can exceed $0.25 \mathrm{~m} / \mathrm{s}$ (Figure 8). The flow accelerates as it passes over the top of the cover and downstream of the structure the flow profile shows the effect of having passed through / around the jacket structure producing a slower near bed velocity profile.

This is confirmed when we look at the cross-sectional flow profile (Figure 9). The cross-sectional flow indicates that the flow enters the structure at the ambient flow velocity, before reducing in magnitude within the structure and increasing again on exit. The majority of the flow profile occurs between $0.5 \mathrm{~m}$ and $2 \mathrm{~m}$ above the seabed.

Areas of bed shear stress in excess of $0.15 \mathrm{~Pa}\left(\mathrm{Nm}^{-2}\right)$ will have preferentially experienced erosion. The predicted bed shear (Figure 10), in the vicinity of the structure, indicates that there is a general decrease in shear at the entrance of the structure. Inside the cover, there are local areas of higher bed shear due to the flow interaction with the skid. At the exit porch there is a relatively large area of increased bed shear; this is due to the channeling of the flow from within the cover out through the opening.

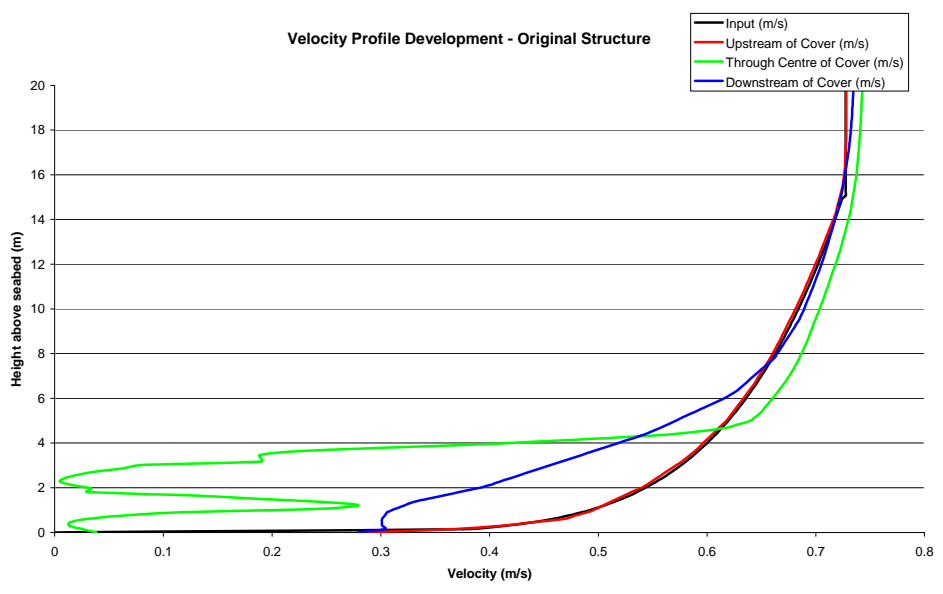

Figure 8. Velocity profiles with original structure.

Outside the concrete cover, bed shear is higher due to the acceleration of the flow around the structure, specifically with a high intensity streak extending to the north-west. As the flow is slightly skewed to the structure, it is considered that this high shear area is due to corkscrewing of the flow off the north-east face of the structure. This turbulence flow can be seen when reviewing the streamlines around the structure, as shown in Figure 11. It is expected that the situation on the reverse flow direction will be (approximately) mirrored. 


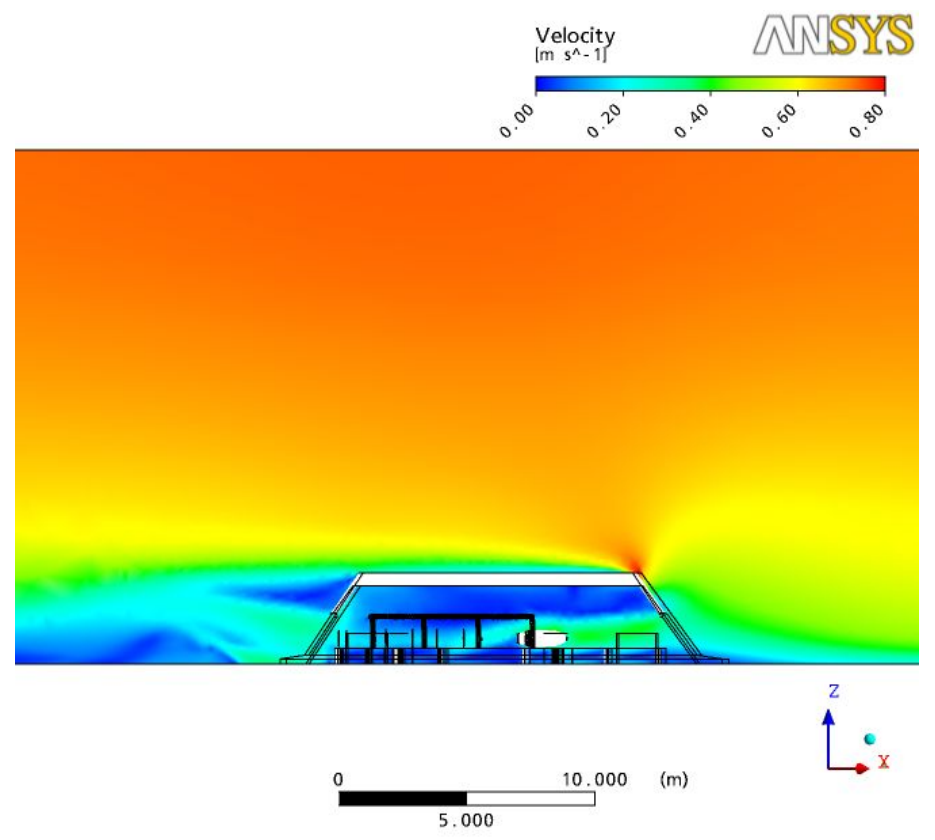

Figure 9. Velocity field through centre of cover - flow from right to left.

Bed erosion took place inside the cover but we are not aware of the erosion pattern around the cover. Frond mats were installed along the north-east and south-west facing edges which it is presumed would have prevented scouring in those areas. Scour was expected to occur inside the structure due to the local flow interaction with the skid and the exit flow acceleration and associated turbulence. This occurs for both tidal flow directions. The action of waves in stirring up sediment would have provided additional disturbance for sediment to be transported by the current.

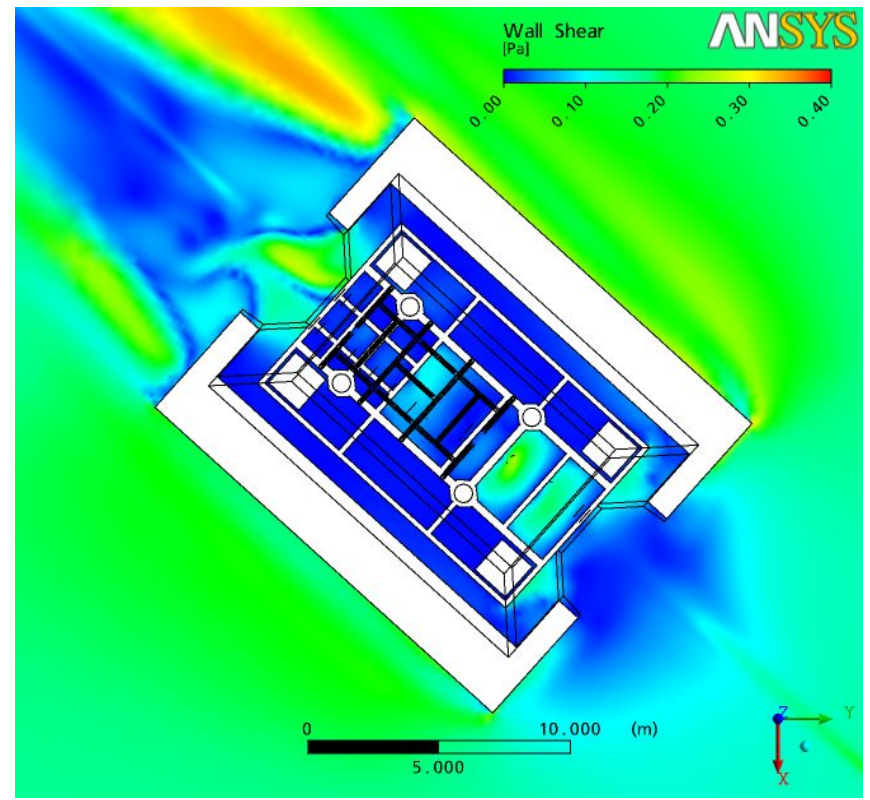

Figure 10. Bed shear stress in and around the structure at 500 seconds of simulation time.

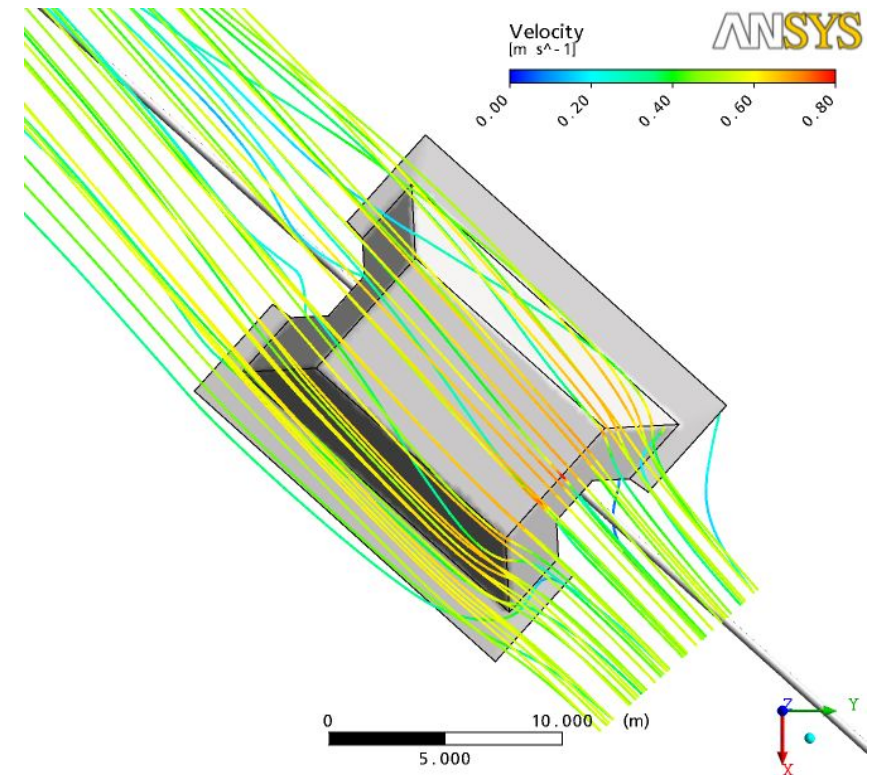

Figure 11. Streamlines showing flow interaction with cover unit - flow from bottom right to top left.

\section{RESULTS FOR REVISED STRUCTURE}

Results from the existing structure, provided above, indicate that the model predicts areas of bed shear which corresponded to the scour areas observed on the seabed following the installation of the original structure. Therefore the model was revised to represent the structure of the proposed revised works with the porches at either end of the structure, as well as concrete mattresses around the perimeter of the structure and over the first $15 \mathrm{~m}$ of pipeline at either end. In addition, a second layer concrete mattress was specified near the porch entrances to reduce flow into the concrete cover. The unstructured mesh representation of revised structure is shown in Figure 7. The build up of sediment in the frond mats placed over the concrete covers was not included in the simulations but sediment build up would provide further streamlining of the structure.

Analysis of the flow velocities showed the revised structure reduced the flow velocities upstream of the porches and in addition, comparing Figure 12 with Figure 8, the reduced area of the porch opening significantly reduced velocities at $1 \mathrm{~m}$ above the seabed within the concrete cover $(\sim 0.02 \mathrm{~m} / \mathrm{s})$. The flow pattern at $3 \mathrm{~m}$ above the seabed was very similar to the flow pattern for the original structure. The crosssectional flow through the domain and concrete cover (Figure 13) confirmed the reduced flow velocity through the structure. 


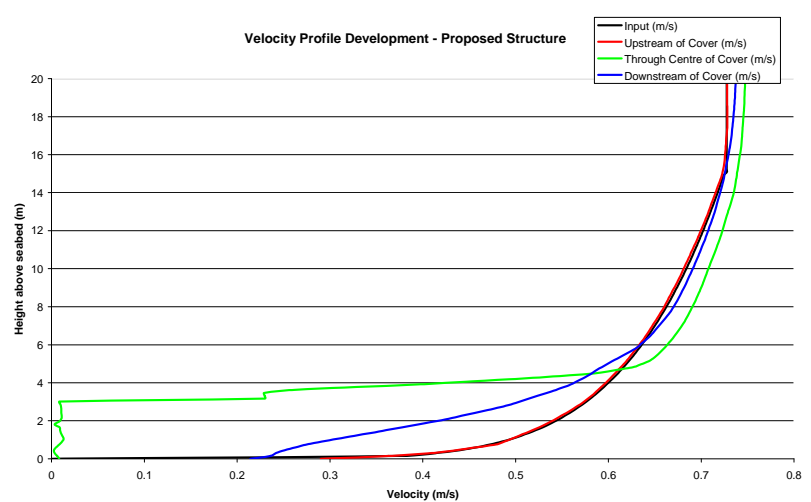

Figure 12. Velocity profiles with revised structures.
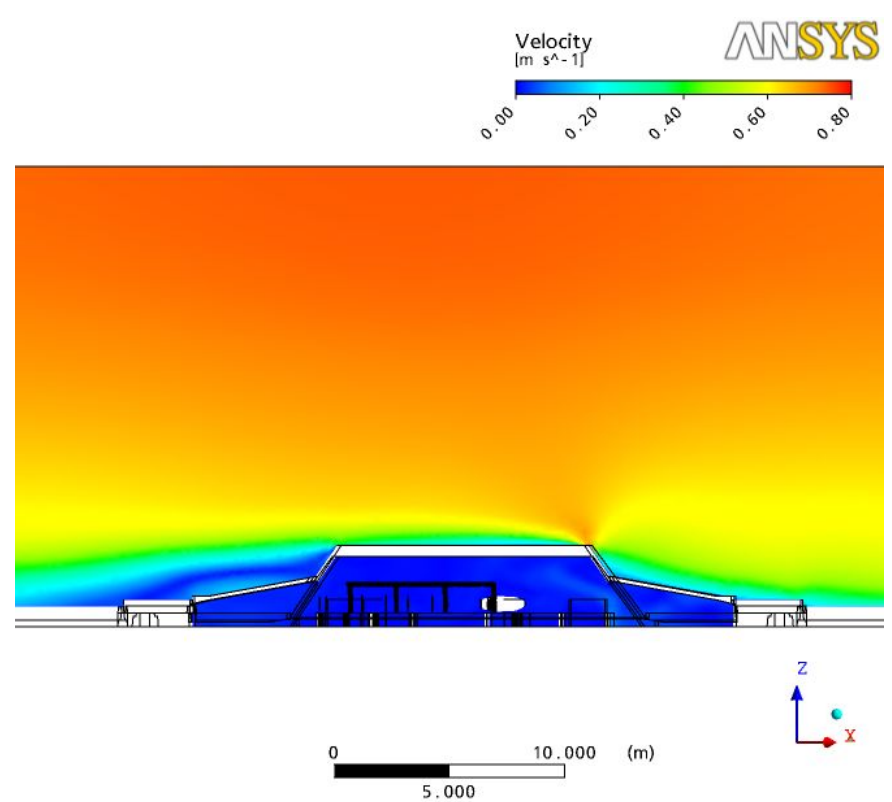

Figure 13. Velocity field through centre of cover - flow from right to left.

Due to these lower flow velocities, the bed shear stresses within the concrete protection cover are significantly lower than those predicted for the existing structure. The concrete mattresses around the perimeter of the structure also provide additional protection for the seabed. Bed shear predictions around these concrete mattresses are only slightly higher than the ambient bed shear stresses, see Figure 14. The high intensity bed shear streak is present again, although it appears to have moved slightly further north, with the concrete mattresses partially protecting the bed from the higher shear. Within the concrete cover there is very little bed shear stresses with the maximum predicted bed shear being only $0.03 \mathrm{~Pa}$ (i.e. well below the shear stress for sediment motion). The streamlines around the proposed structure were similar to those predicted for the original structure.

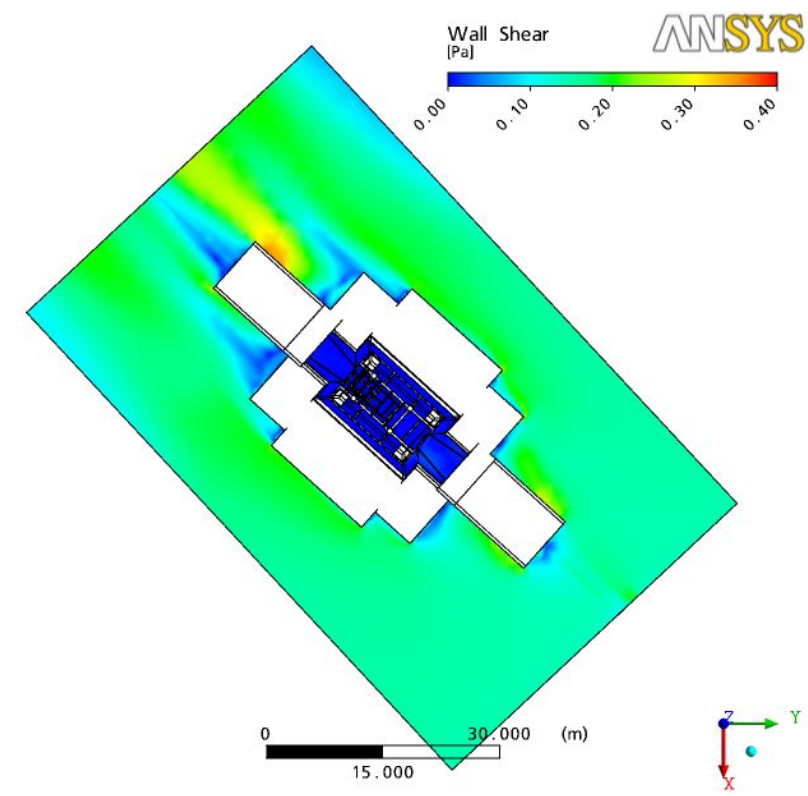

Figure 14. Bed shear stress in and around the structure at 500 seconds simulation time.

\section{DISCUSSION OF RESULTS}

The velocity and shear stress field within and around the structure confirmed that the following benefits were achieved with the revised works design:

1. The flow induced bed shear stress within the protection structure due to the modeled flow conditions is very low (Figure 13) and will be insufficient to generate sediment transport within the structure. This reduces the risk of erosion within the covered area around the Wye-piece skid.

2. The proposed extent of concrete mattressing around the structure was sufficient to prevent undermining of the concrete protection cover by the modeled flow conditions.

Figure 14 shows an area of enhanced stress is present around the outer extent of the mattresses and in particular on the edge of the mattress over the pipeline at the downstream extent of the protected area. With the flow from the north-west the situation will be mirrored approximately on the seabed at the other end of the mattresses. The mattresses specified were flexible to take account of scour that will occur at their outer edges, i.e. so that they can settle into the local scour pits that are formed without producing an unstable mattress configuration.

It was noted that whilst the dominant flow scenario, from a sediment transport point of view, was modeled currents from other directions, with different speeds, will be operating at other times. Also there will be some periods when wave action may produce stirring of sediment at the seabed. Wave action will modify the shear stress and scour patterns locally and will amplify the scouring that has been initially caused by the local flow field. The combination of currents and waves from 
directions other than those modeled may cause local scouring of the seabed around the protection structure.

Following examination of the layout of the mattresses and shear stress fields in Figure 14 it was concluded that these will provide sufficient protection to prevent local scour from undermining the concrete protection cover.

\section{CONCLUSIONS}

Observations of scour have been made at an existing subsea concrete gravity protection cover for a pipeline Wyepiece and a structured assessment was completed to demonstrate the causes of the scour. This was used to inform the development of a revised scour-resistant structure that could be installed. As a part of the assessment an advanced 3-dimensional Computational Fluid Dynamics (CFD) modeling simulation was carried out to demonstrate the detailed pattern of flow interaction with the subsea structure and seabed. Results from the CFD model have proven to form an effective basis on which to inform the design of scour resistant subsea structures in areas of seabed which are prone to scouring.

The following conclusions have been drawn from the analysis:

1. The seabed sediments at the site are mobilized by current speeds which equal or exceed those of the mean spring tides. Because of the way in which the tidal flow interacts with the structure scouring of the seabed will occur under these conditions, where the bed is not protected by anti-scour mats. Currents that are faster than the mean spring tide will mobilize a greater mass of sediment and produce faster, and possibly deeper, scour development.

2. Detailed computational modeling of the tidal current flow field in 3-dimensions has analyzed the interaction of the flow with the Wye-piece concrete protection cover and mattresses, with the pipeline and Wye-piece skid represented inside the cover. The flow results were converted to bed shear stress which is a measure of the force exerted on the bed by the flow. Away from the structure the ambient bed shear stress was as expected whilst locally in and around the structure variations due to the local flow patterns and turbulence change the bed shear stress leading to gradients in sediment transport and scouring.
3. For the original structure configuration the results showed that scouring would have taken place inside the open porches of the protection cover. Scour would also have taken place in the seabed around the cover where it was not protected with frond mats and downstream.

4. The results from the original structure were used to inform the development of the revised structure configuration. The results of the analysis with the revised configuration showed that scouring would not take place inside the protection cover. It also demonstrated that the proposed layout of flexible concrete mattresses would prevent the main effects of scour from undermining the protection cover.

The results have demonstrated, by comparison with field observations of scour development, that the CFD approach is a powerful tool to research and inform effective scour control measures within an integrated structural, geotechnical and hydraulic study. Running the CFD model with a free-surface and a larger computational domain has also been used to evaluate wave and current loading on the structure. Those results - not presented in this paper - have provided the forcing terms (Fx, Fz, My) for a Finite Element analysis of the resistance of gravity protection cover units to sliding. The CFD method is versatile and has been applied to deal with incombination effects with other structures such as multiple pipelines, cover units, anti-scour mattresses and steel jackets.

\section{ACKNOWLEDGMENTS}

The material presented in this paper is published with permission of Shell (U.K.) Ltd and the views expressed in the paper are those of the authors.

\section{REFERENCES}

[1] Soulsby, R.L., 1997, Dynamics of Marine Sands, Thomas Telford, London.

[2] Whitehouse, R.J.S., 1998, Scour at Marine Structures, Thomas Telford, London.

[3] Sumer, B.M. and Fredsøe, J., 2002, The Mechanics of Scour in the Marine Environment. World Scientific. 